\title{
Report: Developing Teacher Educators for the Lifelong Learning Sector: crossing borders
}

\author{
Avis, J. Fisher, R. Simmons, R. Canning, R. Morgan-Klein, B. \\ University of Huddersfield University of Stirling \\ HUDCETT \\ Context
}

Whilst there is a significant body of literature on school teacher training in the 'home nations', little comparative research exists on Vocational Education Teacher Training (VETT). In order to begin to address this deficit, in April 2010, the Consortium for Post-Compulsory Education and Training (CPCET) awarded a research grant of $£, 4,000$ to Robin Simmons from the University of Huddersfield to lead a project examining VETT in England and Scotland. The research aimed to compare and contrast the VET'T systems in the two countries, and to explore the differing trajectories of this provision. The research team was drawn from the two biggest providers of VETT in England and Scotland - the Universities of Huddersfield and Stirling. Robin Simmons worked on the project alongside Huddersfield colleagues James Avis and Roy Fisher, and Roy Canning and Brenda Morgan-Klein from the University of Stirling.

\section{Methodology}

Policy documents and academic literature on VETT from both countries were examined and interviews and focus groups with a group of Teacher Educators from both countries were conducted. Questionnaires focusing on the Teacher Educators' views on professionalism, their conceptions of good practice, and employer attitudes to VETT were also used. Fieldwork was carried out when the Huddersfield team visited Stirling in April 2010, and during a reciprocal visit to Huddersfield the following month. Reflecting the different delivery structures in the two countries, the make-up of the two groups of Teacher Educators taking part was as follows:

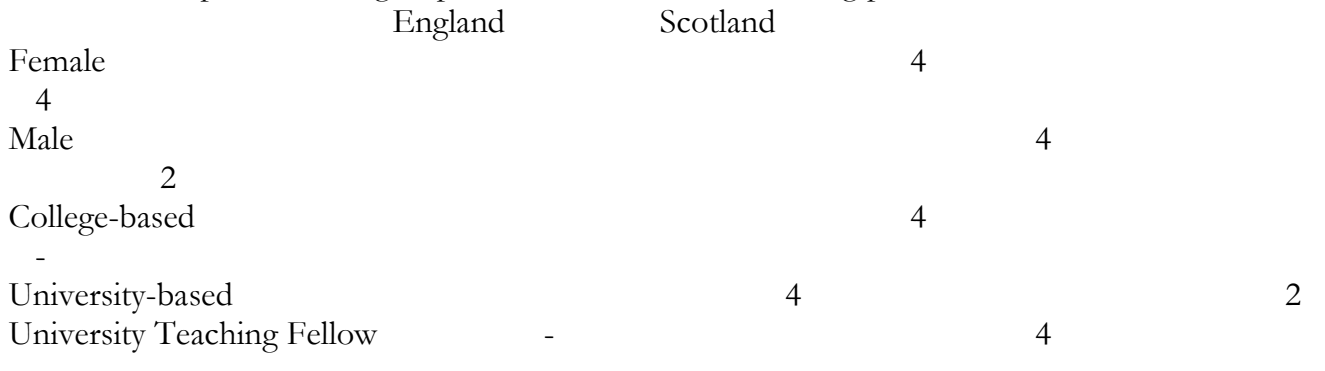

\section{Findings}

Over the last decade, VETT in both countries has undergone far-reaching change. Most of this change derives from the 'competitiveness settlement' whereby Vocational Education has been identified as central to improving workplace skills and economic competitiveness, as well as promoting social inclusion. Consequently, there has been significant pressure to reshape VETT in order to develop a more highly performing and productive teacher workforce. However, despite similarities in the political environment and demands for reform in both countries, there are marked differences in the way VETT has developed and is delivered in England and Scotland. Some of the project's main findings are highlighted below.

- Reflecting the size of the teacher workforce and the populations of the two countries, there are many more providers of VETT in England than in Scotland. However, whilst VETT in England is multi-layered and involves numerous providers and agencies, Scottish provision is concentrated in the universities, with only three of these institutions offering programmes. Unlike the situation in England, there are no VETT courses offered by awarding bodies from outside the university sector.

- Scottish provision focuses on training Further Education (FE) teachers, rather than providing for practitioners from a broader Lifelong Learning Sector (LLS), as is the case in England.

- In the Scottish system, all VETT is delivered by university staff (although there is a division between teaching fellows and lecturers, with the former having no formal research role). In England, it is also taught by FE lecturers, and others working in the various parts of the LLS, including practitioners in voluntary and private training providers.

- In England, VETT is much more tightly regulated by external bodies than is the case in Scotland. Although a broad framework for VETT is laid down by the Scottish Government, no detailed system of specification or external validation comparable to the situation in England exists. Inspection regimes also differ greatly between the two countries, with a more performative regime in England.

- The demands of external bodies have presented significant challenges to VETT providers in England. One consequence of this has been a shift towards 'competence', occupational standards, and subject specialist pedagogies; however high levels of regulation have ensured some degree of consistency across provision in England. 
- In contrast, whilst Scottish providers have, at least in theory, more freedom to devise and deliver VETT according to their own priorities, a marketised system with little state regulation has led to intense competition on the basis of cost. This has meant 'a race to the bottom' and more truncated, low cost, 'generic' programmes.

- Therefore, in both systems there are different pressures driving narrow conceptualisations of practice. However, despite this, in both countries we found Teacher Educators attempt to exercise professional autonomy, and have an interest in developing the critical capabilities of their trainees. In both England and Scotland Teacher Educators try to develop pedagogic skills and an understanding of societal issues. But this arises from the commitment of educators rather than as an inherent feature of the systems.

The following quotations provide some flavour of our findings. Scottish Teacher Educators commented: "I think one of the positive features is... there is still enormous scope to design a curriculum and deliver that curriculum and... although there are standards they inform that teaching and it's not prescriptive. And we don't have a regular framework where external bodies will come in and look at that on a regular basis..."

"Although we had a national qualifications framework, which is highly developed in Scotland and probably more so than in England, the volume of credit wasn't specified though the level of credit was and that, of course, created a downward pressure...It's the college who will decide who the provider is...In many cases it comes down to the basic principle that it's cheaper'.

"The English model is probably where we were six or seven years ago with two year part-time programmes... we're now a one year part-time programme with three modules and all the other colleges in Scotland are the same. We do not have two year part-time courses... [We've] only got ...one observation".

From our English focus group:

" $[F]$ rom the outside the attraction of the [English] model is that it's got that consistency and it lends itself to a two year programme, but the downside of that is the amount of performativity and meeting their standards which is very taxing. So although it seems attractive from the outside once you're in it, it doesn't feel very nice. So it's swings and roundabouts".

\section{Project outputs}

The project's findings were presented at conferences in Helsinki, Huddersfield and Warwick during 2010 and 2011.

The following publications based upon the research provide further detail about the project.

Avis, J., Canning, R., Fisher, R., Morgan-Klein, B., Simmons, R. (2011) 'Vocational Education Teacher Training in Scotland and England: Policy and Practice', Journal of Vocational Education and Training Vol. 63, No. 2, pp. 115-127. Avis, J., Canning, R., Fisher, R., Morgan-Klein, B., Simmons, R. (2012) 'Teacher Education for Vocational Education and Training: a Comparative Study of the Scottish and English Systems set Within a European Context' Educational Research [forthcoming]. 